\title{
Knowledge Transfer In Virtual Communities
}

Ayman Abuhamdieh, (Email: sdayman@isugw.indstate.edu), Indiana State University

\begin{abstract}
Many organizations are providing customer support and service through building virtual communities of users and practitioners. Within these communities, knowledge is exchanged and transferred on a continual basis. But what type of organizations are actually relaying on such communities? And what are the mechanics of knowledge transfer in these communities? This study sets out to identify the organizations most likely to use virtual communities in their customer support operations through a survey of the Fortune 500 organizations. It also analyzes the process of knowledge transfer mechanics within these virtual communities by focusing on four technologyintensive organizations: Microsoft, Dell, Amazon.com, and eBay.com. Study conclusions and recommendations for future research are presented.
\end{abstract}

\section{INTRODUCTION}

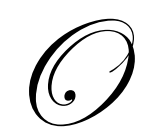

rganizations in different ecommerce activity domains (clicks and mortars and pure plays) are increasingly using virtual communities in their operations. Their use includes building relationships with customers through online delivery, feedback, and enabling better communications within the organization on its intranets and extranets (Dickey 2003). Clicks and mortars, or organizations that have web as well as physical presence, use these communities to support the current organizational supply chain operations. This is especially true for the end of the supply chain where the organization is providing post-sale service and customer support.

To find these virtual communities on an organization's web site, links could either be easily found on the homepage, or they could be hidden under one or more web site layers. Some organizations call them simply communities, or community, others call them forums or newsgroups, or even e-tribes (Domingue, Stutt et al. 2003). Whatever the name is, these communities are taking an increasingly important role in companies' operations today.

A virtual community could be defined as a collective, collaborative, electronic, internet-based, communication sustained by a group of participants for a purpose. Groups of people with specific interests communicate in cyberspace with each other using different types of mediums, such as email, forums or bulletin boards, newsgroups, and chat rooms. The most widely used medium of communication in virtual communities is forums or bulletin boards (both terms will be used interchangeably throughout) (Lee, Vogel et al. 2003).

There are different types of virtual communities, such as communities of interest, goal-oriented communities of interest, learners' communities, and communities of practice (Henri 2003). Communities that exist in the world of ecommerce could take the form of any of these community types. In fact, some communities join two or more types together. For example, a community of practice (such as trumpet players who meet online at www.trumpetherald.com) is considered a community of interest, and at the same time they provide a special section for new-coming learners, in addition to the commerce activities that take place there.

Organizations are using virtual communities to reach beyond increasing the communication effectives within the organization, or between the organization and its customers. They are being used to achieve knowledge transfer. Most of what an organization works with is data and information that is applied in a context, with some of its aspects becoming knowledge in the minds of its users. Organizations today are turning to creating virtual communities to serve their customers as part of their CRM (Customer Relationship Management) programs. Examples are ample on 
the web for organizations that created those communities, such as Microsoft, Dell, Western Digital, and many others. But which organizations are actually using virtual communities? And what are the mechanics of knowledge transfer taking place in these communities?

This study conducted a full survey of the Fortune 500 list to identify companies who actually use virtual communities as part of their operations. The study profiles the organizations that use virtual communities, and identifies the roles they play in the organization's operational context. A qualitative assessment of the relationship between organizational use of virtual communities and knowledge transfer occurring in these communities is discussed. Finally, a suggested model representing the interactions that takes place between the two types of virtual communities and the organization is presented.

The following sections present the literature review, methodology used, the results of the survey of the Fortune 500 companies, and four virtual communities hosted by four organizations (Microsoft, Dell, Amazon.com, and eBay). The study concludes with a discussion of the research findings, a proposed virtual communities interactions model, the conclusions, and directions for future research.

\section{LITERATURE REVIEW}

Despite of the extensive discussion in the literature about the concept of virtual communities, there is yet to be a consensus on its definition. Several studies (Howard 1993; Hess 1995; Romm and Clarke 1995; Erickson 1997; Carver 1999; Hagel 1999; Craig and Zimring 2000; Ho, Schraefel et al. 2000; Jones and Rafaeli 2000) presented a definition of the concept of a virtual community with different emphases on its aspects. For example, Erickson (1997) defines a virtual community as a "long term, computer-mediated conversation amongst large groups." So the emphasis here is on the participants of the community and the medium they use, but it does not refer to any relationship building as a result of this 'conversation' or interaction.

The different definitions of virtual communities and a comparison between them is discussed by (Lee, Vogel et al. 2003). After they extract the conceptualizations of virtual communities from several studies, they combine them with a 'unified' definition of a virtual community as "a cyberspace supported by computer-based information technology, centered upon communication and interaction of participants to generate member-driven contents, resulting in a relationship being built up." (Lee, Vogel et al. 2003). This is an inclusive definition, but it implies a cause-effect interaction, which might not apply to all settings. For example, a forum established for a class in an educational institution could be a community gathered around a goal, such as class assignments, which might or might not result in a relationship being built.

Hence, for the purposes of this study, a virtual community is "a collective, collaborative, electronic, internetbased, communication sustained by a group of participants for a purpose." It is collective in the sense that groups of people are necessary for the establishment and sustainability of a virtual community. The number of persons needed to establish a community and keep it alive is difficult to determine (and suggested for future research investigations), but a certain 'critical mass', along with other factors, is needed for the survivability and continuity of a virtual community. Collaboration is one of the important aspects of a virtual community, and one of the reasons for establishing one, as in the educational and the industry sectors, for example.

Virtual communities could be created for different reasons, such as having a common interest, building relationships, entertainment, and performing transactions (Carver 1999; Hagel 1999). The range of interests that an online community satisfies covers every conceivable topic, from music to politics, and from education to technology. Building forums to perform transactions or to support business activities is increasingly used in the business world today. Many corporations, such as Dell, Western Digital, and Microsoft - to mention a few from the technology sectorhave dedicated forums rich with information contributed from both: the corporations, and individual participants.

The most widely used form of a virtual community is the forum or the bulletin board (Lee, Vogel et al. 2003). Forums or bulletin boards are online meeting places where users post or 'leave' messages for other users, who 
can read these messages and reply to them at a later date. This type of asynchronous communication frees users from the immediacy of the other communications medium types, such as the phone or the chat rooms.

Organizations that incorporate commerce activities in their operations on their web sites can not guarantee user repeated returns and utilization of the virtual communities' resources. (Bhatt 2004) argues that (dot com) organizations need to have a balance between interactivity, immersion, and connectivity in order to attract customers. Interactivity and immersion could be accomplished using virtual communities on the company's web site. Users interact with each other and with company representatives, and as these interactions deepen, users become immersed in these web sites, thus increasing the chances of repeated visitations.

Users visiting these virtual communities exchange ideas, information, and knowledge. Davenport and Prusak (1998, p. 5) define knowledge as "a fluid mix of framed experience, values, contextual information, and expert insight that provides a framework for evaluating and incorporating new experience and information. It originates and is applied in the minds of knowers. In organisations, it often becomes embedded not only in documents or repositories, but also in organisational routines, processes, practices and norms." The distinction between organizational and individual knowledge is important, but for the purposes of this study, the emphasis is on the knowledge that it is exchanged and contributed by the individuals.

Knowledge description in the literature depends on its classification (Davenport and Prusak 1998; Marwick 2001). Knowledge could be tacit, explicit, individual or organizational. Tacit knowledge is intrinsic or covert in the mind of an individual, while explicit knowledge is extrinsic or overt and has a specific form, such as a document, a rule or a procedure. Individual knowledge refers to the personalized or individuality aspect of knowledge, but organizational knowledge is present in the artifacts, documentation, rules, laws, procedures, policies, and other explicit forms related to an organization as a whole.

Knowledge transfer, on the other hand, involves learning ideas from a source and applying them in a specific context. Within the domain of a forum, this will include the exchange of ideas among the forum users and participants that will lead to the application of those ideas. (Daghfous 2003) defines knowledge transfer in an organizational context as a "process [that] consists of transmission and absorption, culminating in a behavioral change by the recipient firm." So there is an element of learning in the process that leads to a change in the status quo.

The power of forums or bulletin boards is that they enable tacit to explicit knowledge conversion (Marwick 2001). This is a crucial step needed in organizations and in other contexts for sharing ideas and solutions to problems. Through answering questions, posting contribution comments, or asking questions, members and participants in a forum can elicit and share the knowledge they have about a subject matter.

Offline Knowledge transfer between entities faces several hurdles, such as culture clashes, bureaucratic inflexibility, poorly designed remuneration packages, and the weak management of technology transfer offices (Siegel, Waldman et al. 2003). Virtual communities could overcome several of these obstacles, where the need for bureaucratic structures is at is minimum, and the reward from gaining information and knowledge is maximized.

\section{METHODOLOGY}

This study used a comprehensive online web site survey and a case study approaches. To answer the study questions, a complete survey of the Fortune 500 companies was conducted. The Fortune 500 companies were chosen because they represent most of the industrial and service activity in the US market today, they serve most of the business and customers sectors, and all are financially capable of having some kind of a virtual community. Also, all these organizations have web presence that they use to interact with their constituents through ecommerce operations and other business activities.

The full survey was necessary because there is no data about which organizations use virtual communities among the Fortune 500 corporations. The examination process went as follows: each company's web site was examined to see if there is a link on the main page for a virtual community or a forum, since the forums are the most 
widely used forms of virtual communities (Lee, Vogel et al. 2003). If that link is not found on the main page, a search was performed using the search engine provided by that company on its web site for the terms forum and online community. If a link was found that points to a forum or community, it was followed to examine the virtual community adopted.

\section{A SURVEY OF THE FORTUNE 500 COMPANIES}

A complete survey of the Fortune 500 companies was conducted to explore their use of virtual communities. As explained in the methodology section, each company's site was searched for any evidence of the use of virtual communities. The surprising result of the survey shows that only a handful of companies actually use external virtual communities in their operations. These companies are: IBM, Hewlett Packard, Dell Inc, Microsoft, Cisco Systems, Sun Microsystems, Apple Computer, Computer Associates Intl., Advanced Micro Devices, Inc., and Amazon.Com.

The unexpected outcome that out of all the organizations that compose the Fortune 500 list -- which includes energy, health services, communications, food and beverages, banking, insurance, transportation and logistics companies--, only technology companies that are mostly related to computers seems to be the ones who are the most to utilize external virtual communities. As table 1 shows, some of these companies focus mainly on software, others mainly on hardware, and others provide both. AOL and Amazon are online companies providing products and services using computers. Other organizations could have internal virtual communities, but they are not available to the public or their customers who do not have registered accounts with them, and thus are not discussed. Hence, any reference to virtual communities thereof refers to external as opposed to internal virtual communities.

Table 1: Organizations Using Virtual Communities

\begin{tabular}{l}
\hline \multicolumn{1}{c}{ Organization } \\
\hline IBM \\
Hewlett Packard \\
Dell Inc. \\
Microsoft \\
Cisco Systems \\
Sun Microsystems \\
Apple Computer \\
Computer Associates Intl. \\
Advanced Micro Devices, Inc. \\
Amazon.Com
\end{tabular}

The thread that links these organizations is that they either produce computer hardware or software, or use computers to provide products or services. The easiest to find and most visible virtual communities were found on the web sites of Dell, Microsoft, Sun, Apple Computer, and Amazon.com. Searching for the keywords forum, community, or online community returned links that immediately led to the organization's virtual community. Most of these companies use virtual communities as part of their customer support portfolios. This paper will focus on the virtual communities present on the web sites of Microsoft, Dell Inc., and Amazon.com from the Fortune 500 list. The organizations were chosen because each performs a set of activities that is representative of the activities performed by the other organizations in table 1 . eBay will be discussed as well because it is one of the largest ecommerce auction web sites on the Internet today, and it has an extensive virtual community presence on its web site.

\section{MICROSOFT'S VIRTUAL COMMUNITIES}

Microsoft Corporation's main activity is to develop, manufacture, license and support many types of software products for a multitude of computing platforms. The software products include operating systems for servers, personal computers and intelligent devices; server applications for client or server environments; knowledge 
worker productivity applications; business solutions applications and software development tools; consulting services and product support services. Microsoft trains and certifies system integrators and developers.

Microsoft's online businesses are MSN subscription and the Internet products and services. Microsoft is a dominant software provider for desktop operating systems and productivity software. It has close to $80 \%$ of the desktop operating system software, famously known as Windows, and has a substantial market share of the office productivity suite (Microsoft Office). Recently ranked at 47 in the Fortune 500 list, Microsoft is the number one in market capitalization ( $\$ 277$ billion). Microsoft has a huge market base of customers that use its products both at home and at work. (http://money.cnn.com).

Microsoft has several virtual communities. In specific, there are more than 2000 public news groups, over 50 community web sites, and it hosts about 30 chat sessions per month in the technical communities section (www.Microsoft.com). Other communities are hosted on its MSDN (Microsoft Developer Network) and are used to provide technical assistance to its product users and a forum for its product lines developers. The technical community page is displayed in figure 1. Access to these communities is free of charge and provides a wealth of information that is contributed by both users and Microsoft support personnel.

Microsoft communities are further divided into product and technical communities, World wide community sites, and third party community sites. The product and technical communities' page has an extensive list of Microsoft's products. Clicking on any of the links opens a new page with a more detailed list of the specific lines of that product, and a list of discussion groups related to that line (for example, the Microsoft Office product has several lines, such as Word, Excel, and FrontPage, and each has its own discussion board.)

The World wide community sites page has links to fifteen different discussion boards worldwide, such as China, France, Germany, among others. Clicking on the China link takes the user to a Chinese community discussion board that uses the Chinese language. The same is true for every country link on that page. The third party community sites are hosted by other organizations or companies, but they discuss Microsoft-related products and technologies. Examples include: About.com Desktop video, PC mechanic, and the PC Guide Forums.

It is very clear that Microsoft uses virtual communities as an essential part of its service to its community of customers and developers. These communities enable Microsoft to cater to all its product users, whether they are individuals or organizations (organization members would participate as users in these communities.)

These users interact with each other and with Microsoft technical support through participating in these communities. This interaction is done mostly through asking or answering questions. This creates a massive "rich" knowledge base that has much more value than the knowledge base provided by Microsoft's documentation articles solely, because that "rich" knowledge base, rife with different theoretical and practical contributions is mixed with individual experiences that enrich the standard guidelines found in traditional knowledge base articles. 
Figure 1: Microsoft's Technical Communities Web Site

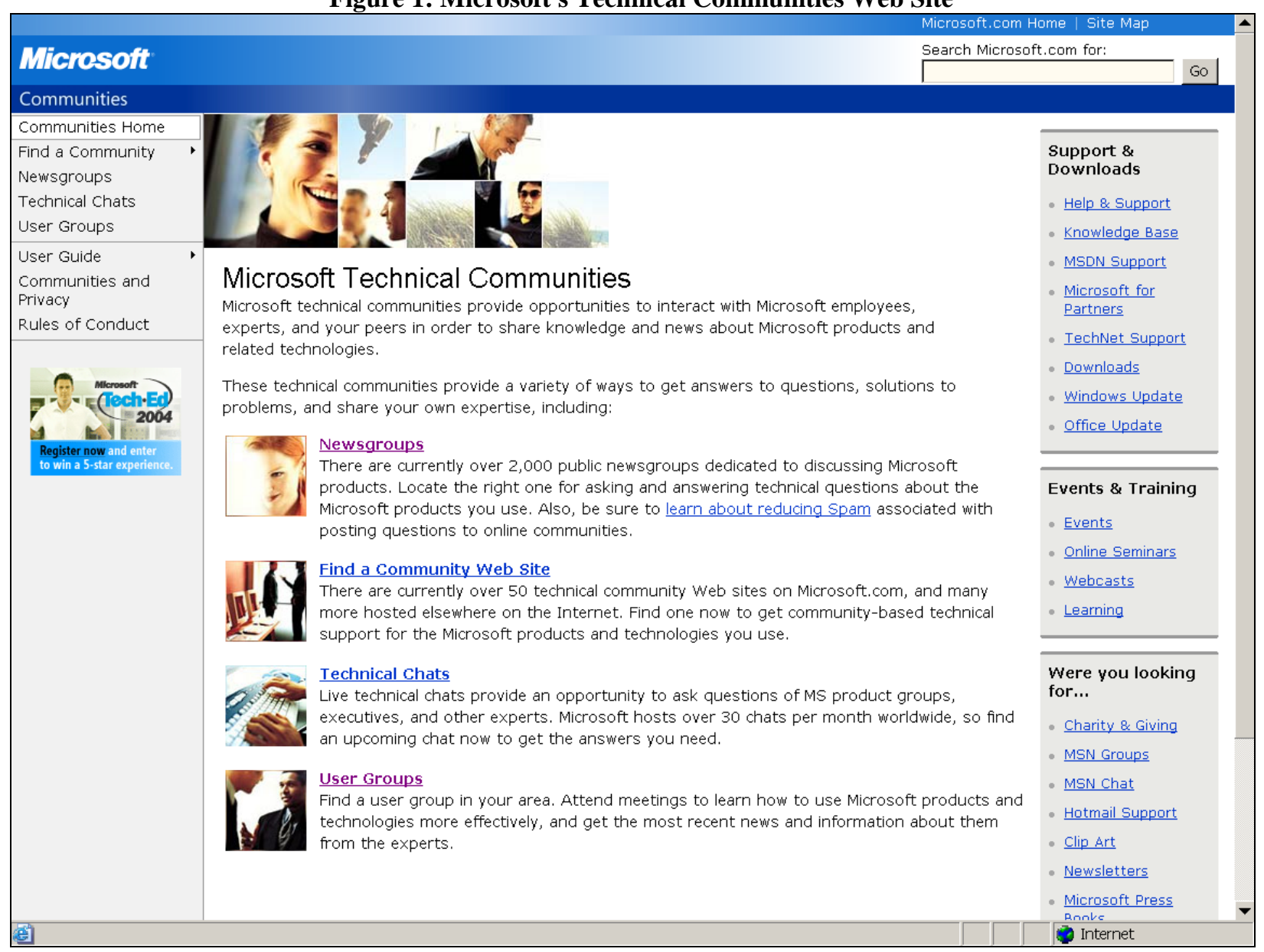

\section{DELL'S VIRTUAL COMMUNITIES}

Dell Inc designs, develops, manufactures, markets, serves and supports a wide range of computer systems. Its primary products include enterprise systems, notebook computers and desktop computer systems. It also provides professional consulting, custom hardware and software integration, leasing and asset management, network installation and support and onsite services. It has operations covering the five continents. It has about 30,000 employees, and a market capitalization value of $\$ 81$ billion (http://money.cnn.com). Dell engages in ecommerce through providing customers with the ability to buy any product or service that Dell sells online. Users simply choose the product or service they wish to purchase, use the payment option, and pay online through a secure web page.

Dell has its virtual community under its service and support offering. Its virtual communities are divided into message boards that deal with different aspect of a PC, such as the BIOS, peripherals, audio, and so forth. It is also organized according to the product line offerings of Dell, such as its different product lines of PCs, servers, printers, and other products.

Going into any of these boards takes the user into a threaded discussion of the main topic of that particular board (audio, for example). So any users who have any problems with their computer's audio would come to that specific discussion board, post a question, or search for an answer about the specific problem he or she is facing in their computer. Users are encouraged to read the FAQs (Frequently Asked Questions) before they post their own questions because someone else could have posted that question before and the answer is already available, without 
any need to post another discussion thread. Figure 2 shows a capture of Dell's online community forum that discusses audio issues.

Dell also provides cross functional support on its community web site for the products that are used on its systems, such as the operating systems that are provided by Microsoft. When installing or updating software or a hardware component, conflicts might occur that could render the computer system unstable. Thus, these communities provide the answers to the users' questions about most of the problems they face.

As is with the case of Microsoft, the knowledge that is created on Dell's community sites and discussion boards is rich with user experiences and contributions, which provides solution seekers with the answers they need for the problems they face when using the products of these companies. Knowledge transfer is taking place on these web sites through the dialogue and idea exchanges between customers themselves and customers and company support staff.

Figure 2: Dell's Online Community Forum

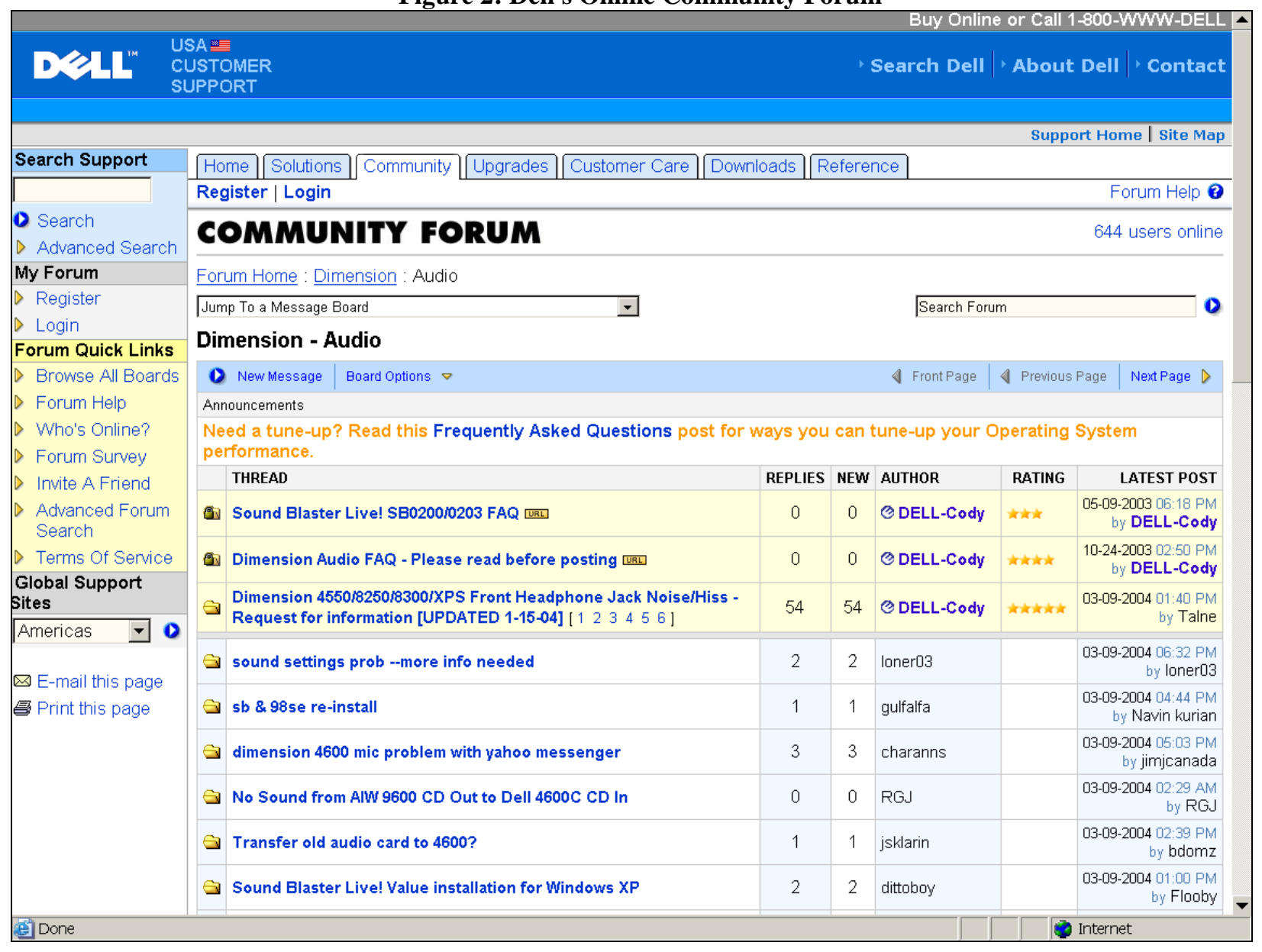

\section{AMAZON'S VIRTUAL COMMUNITIES}

Amazon.com is an online store front. It started as a book seller, then expanded its business or domains to other areas, such as apparel and accessories, electronics, toys and games, DVDs, and tools and hardware. Amazon 
employs about 8000 workers, was ranked 408 in the recent Fortune 500 list, and has a market capitalization of $\$ 17$ billion (http://money.cnn.com).

Amazon.com has its virtual communities in a discussion board form under three categories: Computer software and games, customer reviews, Auctions, zShops, and marketplace. Figure 3 shows a capture of the customer review discussion board. As with the other discussion boards that were described for Microsoft and Dell, discussion boards here take the form of threaded discussions. Users post their messages on the board for others to read and respond to their posts. What is different in the case of Amazon.com is that discussions are between users, or are peerto-peer, as opposed to what Dell and Microsoft have, which includes participation from the companies' customer support staff, in addition to the peer-to-peer discussions.

Figure 3: Amazon.Com Discussion Boards.

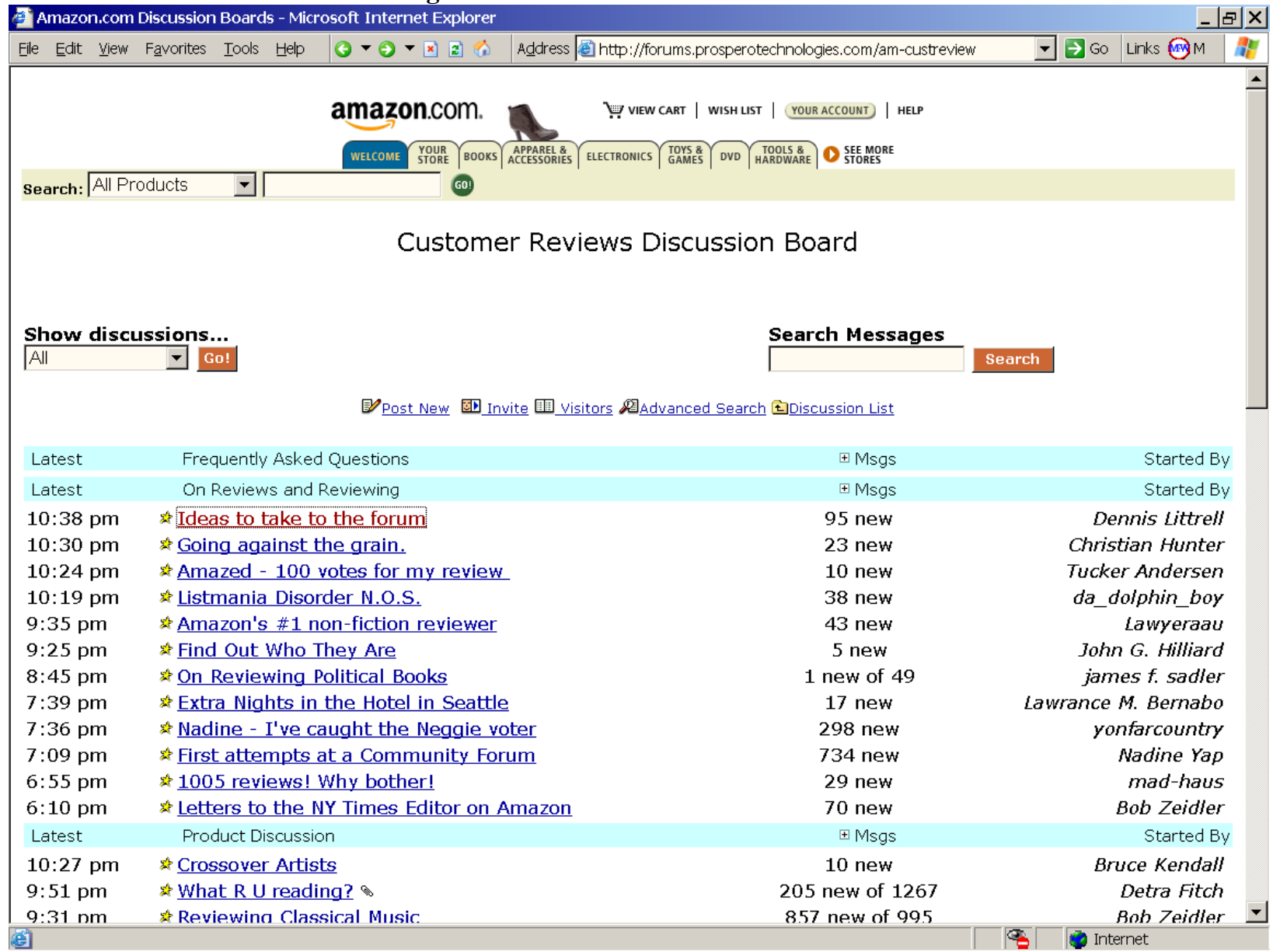

The nature of the posts on these boards differ from Microsoft's and Dell's in that they are focused more on product reviews rather than posting a problem with a product or technology and looking for answers on the board for it. Although the content of the boards is different in nature, there still is knowledge created from the participation of users in these boards. 


\section{EBAY'S VIRTUAL COMMUNITIES}

eBay operates an online market place through the web site eBay.com. It developed an auction web-based community in which buyers and sellers are brought together to buy and sell new and used items such as collectibles, automobiles, jewelry, consumer electronics and many other items. It also provides offline traditional auction services for fine art, antiques, collectibles, and collector cars. Through their wholly owned and partially owned subsidiaries and affiliates, eBay operates online auctions in the United States, Asia, Europe, and Oceania (http://money.cnn.com).

eBay has an extensive virtual community presence on its web site, and a capture of it is shown in figure 4 . Although eBay is not a Fortune 500 company, it is a leading online auction house for all kinds of items, big or small, cheap or expensive, and it has world wide operations. Its use of virtual communities is similar to what Amazon does, albeit eBay uses virtual communities much more extensively than Amazon.

eBay has four categories of forums: talk, news, events, and people. Under the talk section, it has the major discussion boards, which include: community help boards, category specific discussion boards, general discussion boards, workshops, and giving works boards. These boards in particular and the other boards in general facilitate peerto-peer user interactions. Sellers and buyers on eBay can benefit tremendously from the information posted on these boards, such as how to open accounts for buyers and sellers, how to make the seller's items jut above other sellers' items, how to link pictures from other servers, among many other topics.

All of the communities discussed so far post rules of participation for users to abide by and follow, such as avoiding coarse language, posting relevant topics in the correct boards, and formulating questions in an understandable manner. These rules are strictly enforced, violators are held responsible and disciplined according to the severity of the violation, which could be from simple reminders of the rules, to outright banning from participation.

\section{DISCUSSION}

Virtual communities are cyberspace meeting places for people who want to discuss any issue. Organizations that have ecommerce operations, whether they are 'clicks and mortars' or 'pure plays', are using these virtual communities, but for different purposes, depending on the type of activity that the organizations is performing.

Microsoft and Dell are manufacturers of products. Microsoft is in the software industry (and expanding into the hardware industry), and Dell is in the hardware industry. As producers they need to provide support for their products, and they are using virtual communities instrumentally to help them in that endeavor. Microsoft has literally thousands of virtual communities in different flavors, such as forums or bulletin boards, newsgroups, and chat rooms, and they are deployed on a global basis. Of course, the web is a global forum, but Microsoft went the extra step of creating individualized, country- and language-specific boards. Some of these virtual communities could be viewed and interacted with online (forums), others could be participated in offline (newsgroups) through different types of email clients.

The significance of Microsoft's reliance on these communities is using them as knowledge transfer vehicles for its customers. Although Microsoft has an extensive library or knowledge base in its MSDN network, virtual communities are adding value through blending the individual experiences of users when they applied that knowledge base to the abstract knowledge found in the formal product documentation. As could be easily found by a simple examination of any of the virtual communities on Microsoft's web site, many users follow the instructions that are found in the product documentation that Microsoft provides, but sometimes face difficulties when they try to apply them due to myriads of reasons, such as conflicts with other software or hardware components. If they cannot resolve the problems by themselves, they usually come back to these or other virtual communities in search of answers. 
Figure 4: eBay's Virtual Communities

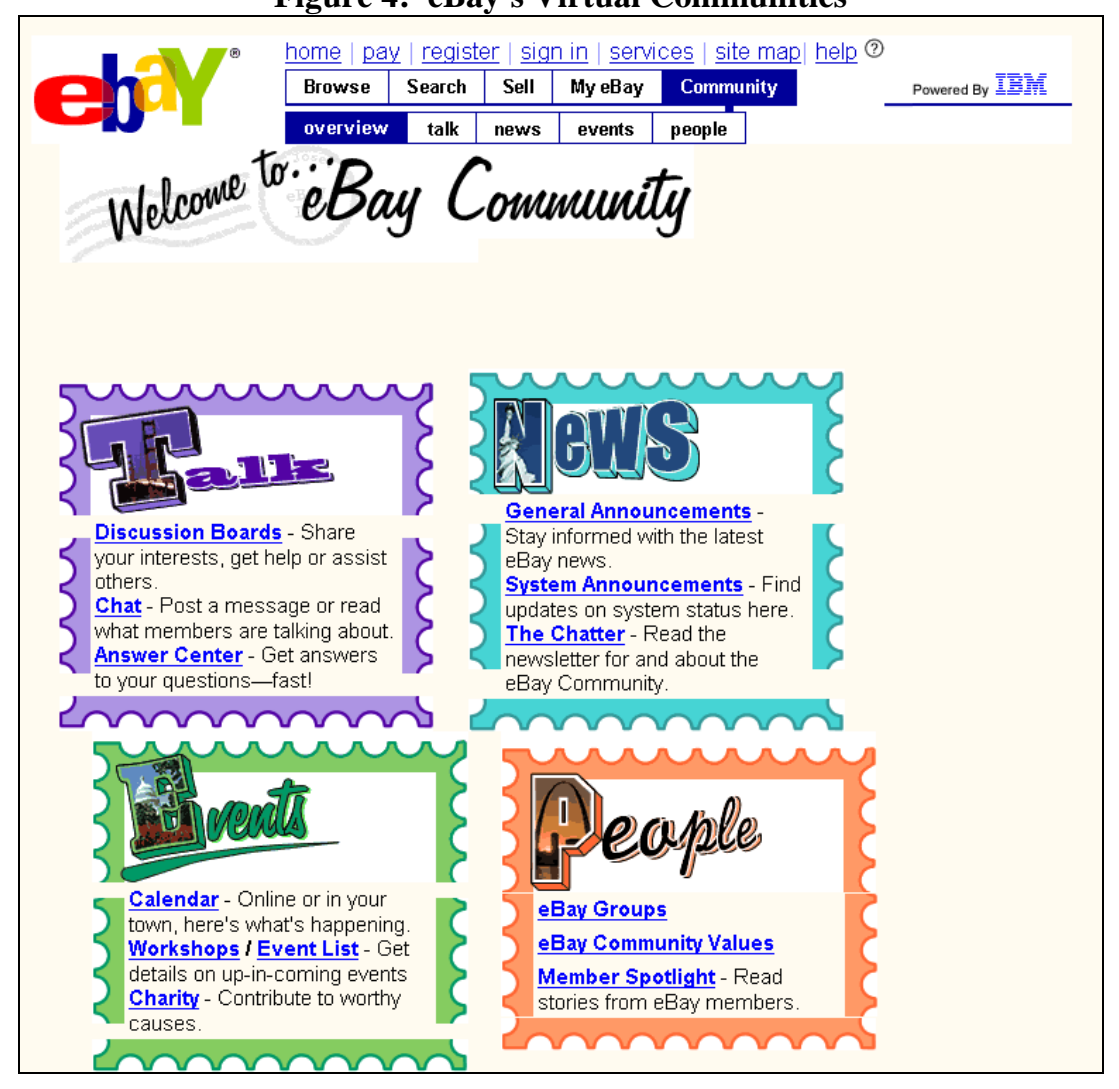

Dell is using virtual communities for the same purpose of knowledge transfer between users, on a peer-topeer basis and through the contributions of Dell's customer support staff. Dell has a knowledge base built from customer contributions, Dell's technicians, and its service providers (http://support.dell.com). However, that knowledge base is static in nature, much the same way as Microsoft's knowledge base is. The virtual communities on these sites provide users with livelier support, faster response, and more relevant answers than even phone or email support could provide.

There is a clear difference in the use of virtual communities between different organizations. Microsoft and Dell are using virtual communities to provide customer support and product development, while the online store front, Amazon.com, and the auction house, eBay are using them as means of creating customer interactivity and peer-to-peer forums for different types of product reviews. Also, Microsoft and Dell have their customer support personnel contribute to these forums, while Amazon's and eBay's forums are mostly peer-to-peer contributions.

Many online store fronts, represented here by Amazon, are using virtual communities to help customers make decisions about buying items through their web sites. Customers would look for books, gifts, games, and countless other items online everyday and many find a review of an item very helpful in making the buying decision. Virtual communities go beyond providing a mere review; they provide the chance for users to interact, ask questions about products' strengths and weaknesses, and product compatibility with other products or items, and so on. This kind of added individual experience is much more valuable than a simple user review of the product, or a manufacturer's description of it.

As a result of the survey of the Fortune 500 companies, technology companies appeared to be the ones using virtual communities as part of their customer support portfolio. Not all technology companies have virtual 
communities. Intel, oracle, and the automobile companies don't have virtual communities on their web sites, although there could be many virtual community sites on the Internet that discuss their products.

Thus, technology companies that have their business model built on providing computer technology-related products or services to individuals, as opposed to businesses, are more likely to have virtual communities on their web sites as either a means for customer support, customer exchange, or developers' forums. This profile is clearly present in table 1, where most of the companies listed provide computer-related products and services.

Why other organizations are not using virtual communities? It appears that when an organization is not producing or selling an item to an end user that he or she will assemble or physically work with, the chances of that organization using virtual communities decreases. Also, participating in virtual communities has the embedded assumption that their users are computer savvy and know their way around virtual communities. Hence, there are assumptions about the organization, its products and/or services, and its customers that must be satisfied for an organization to use virtual communities. Some of these assumptions are uncovered and presented in this study, such as organizations that are operating in computer-related products or services. These assumptions could be further explored in future research.

Different organizations use virtual communities for different purposes, but the mechanism that is taking place in these communities is the same: knowledge transfer. The content in virtual communities could be text, images, or other multimedia format, but the most ubiquitous is text. This text can contain data, information, or knowledge.

Knowledge is an abstract concept describing information that has been taken to the realm of application and beyond the mere processing of data. Knowledge conversion takes place in different forms, from tacit to tacit; tacit to explicit; explicit to tacit; and explicit to explicit (Marwick 2001). Knowledge transfer occurs after tacit to explicit knowledge conversion materializes, where someone takes that converted knowledge one step further into the application domain.

The mechanism of knowledge transfer, which is occurring after knowledge conversion from tacit to explicit and vice versa, is present in the virtual communities of the organizations discussed in this article, and the other organizations listed in table 1. Organizations that go the further step of formalizing some of the content in these virtual communities engage in the explicit to explicit knowledge transformation.

The use of virtual communities should not be restricted to computer-related technology organizations. All organizations can benefit from virtual communities. For example, virtual communities are used in the health care industry to support its customers and patients with information about different kinds of diseases through knowledge transfer (Weis 2003; Winkelman 2003). Patients would participate in these communities and learn more about those illnesses to help them cope. Educational institutions use virtual communities to help students and instructors interact beyond the classroom. Some of these virtual communities are instructor sponsored and some are not (Abuhamdieh 2003).

Organizations can benefit from the information and knowledge found in virtual communities throughout the organizational supply chain management process, and in their organizational scorecards, from the conception of new ideas of products and services, to the design and manufacturing, and finally to product delivery and post-sale services (Kaplan and Norton 1996).

Figure 5 shows the suggested model relationship between the organizational supply chain and its internal and external virtual communities. The figure shows the organizational supply chain or business processes in a typical ecommerce organization. An organization acquires the needed material for production or sales, performs the necessary processing of manufacturing for a production venture, or stacking and accounting for an online store front; and finally markets the product and provides post sale service. The internal virtual communities are composed of the organizational knowledge workers, and the external virtual communities are comprised of end users and other outside parties. 
Figure 5 Internal And External Virtual Communities For An Ecommerce Organization.

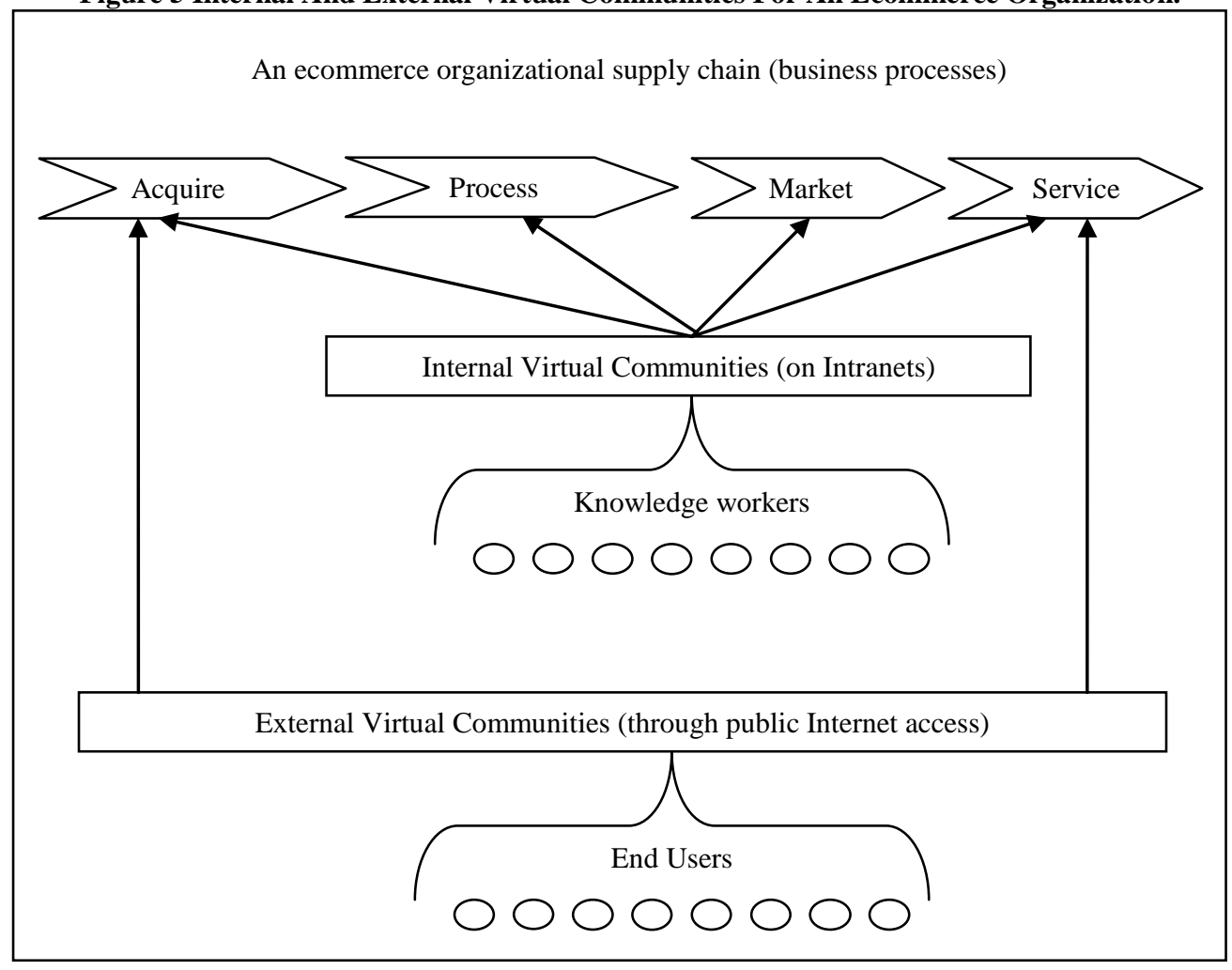

Virtual communities are built either on an organization's intranets, or on its publicly available internet web site, or both. Participants on the intranets are usually the organization's knowledge workers who have exclusive access to its internal business processes and information resources. They exchange ideas and information concerning design, processing, production, delivery, and post-sale service on these virtual communities. This "free-flow" exchange highway contributes to better product development and smoother production process and more efficient and effective customer service. Although more dynamic and immediate mediums are used for knowledge workers to communication, such as phone and instant messaging, internal virtual communities have important contributions as they are part of the asynchronous communications bundle.

End users, such as customers and developers, participate in the publicly accessible virtual communities hosted by the adopting organization. These users can provide the organization with ideas about their product and/or service preferences, which helps in determining the best sources of acquiring them. This takes place at the beginning of the organizational supply chain. Also, these users bring their experiences of using the organization's products and/or services in specific contexts, exchange and learn from each other's experiences, and go through the iterative cycle of application and exchange until their problems are solved (if they were searching for a solution to a problem, for example), which occurs at the end of the supply chain.

Thus virtual communities play a very important role for organizations throughout their entire operations cycle. They learn from their knowledge workers who contribute to these virtual communities about all organizational business processes aspects, and learn from end users who have put the organization's products and/or services to actual use. 


\section{CONCLUSIONS}

Virtual communities are used in full force today to facilitate organizational commerce and ecommerce operations. Organizations use virtual communities in the most widely used form: bulletin boards or forums, as opposed to chat, newsgroups, or email lists. Organizations that provide computer-related technologies are more likely to have virtual communities than other technology organizations. Computer-related software or hardware manufacturers are more likely to have virtual communities as part of their support portfolio, while companies that sell products or services as retailers have virtual communities as a way of providing customers with the necessary means to meet and discuss recommendations about products or services.

Practical implications suggest that virtual communities could be used to provide online and offline customer support for organizations engaging in ecommerce. Large and small companies can easily build virtual communities by using either in-house built technologies, or through buying them from third party sources. These communities are getting the support from the organizations that built them, and thus are an integral component of their offerings.

Theoretical implications point to the role that virtual communities can take in knowledge transfer and knowledge conversion. Virtual communities play an important role in the dynamics of knowledge conversion from tacit to explicit and from explicit to tacit. Knowledge transfer occurs as a result of this knowledge conversion when taken to the world of practice by users.

\section{FUTURE RESEARCH}

Several questions remain unanswered about the use of virtual communities in ecommerce. Is there a critical mass that is necessary for these communities to survive and thrive? What role does organizational support play in the sustainability of these communities? To what extent are these communities effective in their information and knowledge delivery? How can other industries, besides the technology sector, benefit from these communities?

Future research can focus on the user-virtual community interactions. What kind of problems they face when interacting with other members? What makes the user's come back to a community? What is the relationship between the severity of the problems users face and them coming back to interact with a community? Also, future research can focus on the technology used to facilitate user interaction. Should the virtual community system include chat or instant messaging modules? Which technology provides the highest performance under what platform?

Future studies can examine further the assumptions about the users of the virtual communities, the organizations that facilitate their creation and deployment, and the products and services that these organizations produce and provide. Is there a particular skill level needed to participate in these communities? What about the psychological factors that influence user participation, especially that users are contributing to a community of strangers. The relations between technology related organizations and the use of virtual communities could be further explored to see which other technology organizations use internal virtual communities, and organizations operating outside the technology domain.

\section{REFERENCES}

1. Abuhamdieh, A. (2003). Educational Institutions Portal System Utilization: A Student Perspective. Journal of Informatics Education Research 3(1): 29-40.

2. Bhatt, G. (2004). Bringing virtual reality for commercial Web sites. International Journal of HumanComputer Studies. 60: 1.

3. Carver, C. (1999). Building a Virtual Community for a Tele-Learning Environment. IEEE Communications Magazine 37(3): 114-118.

4. Craig, D. L. and C. Zimring (2000). Supporting Collaborative Design Groups as Design Communities. Design Studies 21(2): 187-204.

5. Daghfous, A. (2003). Uncertainty and learning in university-industry knowledge transfer projects. Journal of American Academy of Business, Cambridge 3(1/2): 145. 
6. Davenport, T. H. and L. Prusak (1998). Working Knowledge: How Organizations Manage What They Know. Boston, MA., Harvard Business School Press.

7. Dickey, M. H. (2003). The effect of electronic communication among franchisees on franchisee compliance. Journal of Marketing Channels 10(3,4): 111.

8. Domingue, J., A. Stutt, et al. (2003). Supporting online shopping through a combination of ontologies and interface metaphors. International Journal of Human - Computer Studies 59(5): 699.

9. Erickson, T. (1997). Social Interaction on the Net: Virtual Community as Participatory Genre. 30th Hawaii International Conference on System Sciences, Hawaii.

10. Hagel, J. (1999). Net gain: Expanding markets through virtual communities. Journal of Interactive Marketing 13(1): 55.

11. Henri, F. P. B. (2003). Understanding and analysing activity and learning in virtual communities. Journal of Computer Assisted Learning, Blackwell Publishing Limited. 19: 474-487.

12. Hess, B. W. (1995). Curb Cuts in the Virtual Community: Telework and Persons with Disabilities. 28th Hawaii International Conference on System Sciences, Hawaii.

13. Ho, j., M. C. Schraefel, et al. (2000). Towards an Evaluation Methodolgy forthe Development of Research Oriented Virtual Communities. 9th International Workshops on Enabling Technologies: Infrastructure for Collaborative Enterprises, Galthersburg, Maryland.

14. Howard, R. (1993). The Virtual Community: Homesteading on the Electronic Frontier. Massachusetts, Addison Wesley.

15. Jones, Q. and S. Rafaeli (2000). Time to Split, Virtually: 'Discourse Architecture' and 'Community Building' as means to Creating Vibrant Virtual Metropolises. International Journal of Electronic Commerce \& Business Media 10(4): 214-223.

16. Kaplan, R. S. and D. P. Norton (1996). The Balanced Scorecard, Translating Strategy into Action. Boston, Harvard Business School Press.

17. Lee, F. S. L., D. Vogel, et al. (2003). Virtual community informatics: A review and research agenda. JITTA: Journal of Information Technology Theory and Application 5(1): 47.

18. Marwick, A. D. (2001). Knowledge management technology. IBM Systems Journal 40(4): 814-830.

19. Romm, C. and R. J. Clarke (1995). Virtual Community Research Themes: A Preliminary Draft for A Comprehensive Model. 6th Australasian Conference on Information Systems, Perth.

20. Siegel, D. S., D. A. Waldman, et al. (2003). Commercial knowledge transfers from universities to firms: Improving the effectiveness of university-industry collaboration. Journal of High Technology Management Research 14(1): 111.

21. Weis, R. S., Keith Smith, Craig Nilan, Michael Clark, Fiona Weis, and Joan Kennedy (2003). Communities of Care and Caring: The Case of MSWatch.com. Journal of Health Psychology, Sage Publications, Ltd. 8: 135 .

22. Winkelman, W. J. C. and Chun Wei (2003). Viewpoint Provider-sponsored virtual communities for chronic patients: improving health outcomes through organizational patient-centred knowledge management. Health Expectations 6(4): 352-358. 
